\title{
Article
}

\section{Exploring traumas in the development of talent: What are they, what do they do, and what do they require?}

Savage, Jennifer, Collins, D., and Cruickshank, A.

Available at http://clok.uclan.ac.uk/14682/

Savage, Jennifer, Collins, D., ORCID: 0000-0002-7601-0454 and Cruickshank, A. ORCID: 0000-0002-8893-2341 (2017) Exploring traumas in the development of talent: What are they, what do they do, and what do they require? Journal of Applied Sport Psychology, 29 (1). pp. 101-117. ISSN 10413200

It is advisable to refer to the publisher's version if you intend to cite from the work. http://dx.doi.org/10.1080/10413200.2016.1194910

For more information about UCLan's research in this area go to http://www.uclan.ac.uk/researchgroups/ and search for <name of research Group>.

For information about Research generally at UCLan please go to http://www.uclan.ac.uk/research/

All outputs in CLoK are protected by Intellectual Property Rights law, including Copyright law. Copyright, IPR and Moral Rights for the works on this site are retained by the individual authors and/or other copyright owners. Terms and conditions for use of this material are defined in the policies page.

\section{CLoK}

Central Lancashire online Knowledge www.clok.uclan.ac.uk

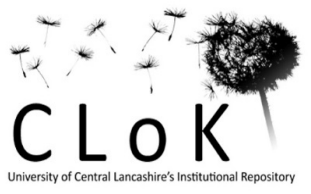


This is a pre-proof corrected manuscript, as accepted for publication, of an article published by Taylor \& Francis in Journal of Applied Sport Psychology, on $31^{\text {st }}$ May 2016, available online at: http://www.tandfonline.com/doi/full/10.1080/10413200.2016.1194910

Exploring Traumas in the Development of Talent: What are They, What do They Do, and What do They Require? 


\begin{abstract}
It has recently been argued that performers benefit from trauma (i.e., memorable challenges) during development. To deepen knowledge in this area, we explored perceived traumas in the development of twenty senior-international performers with a multi-methods, temporal-based design. Results showed perceived traumas were primarily sports-based, recognized from onset of investment, associated with immediately negative but ultimately positive impact, and negotiated through skills that were brought to, rather than generated by, these experiences. The findings provide an interesting contrast to messages in other early trauma-focused research and promote focus on the process and mechanisms of responding to and recovering from traumatic experiences.
\end{abstract}

Keywords: psychological characteristics, social support, learning, deliberate experience, posttraumatic growth 


\section{Exploring Traumas in the Development of Talent: What are They, What do They Do, and What do They Require?}

The primary objective of most, if not all talent identification and development (TID) programs in sport is to select performers with the potential to reach the highest level and then place them in a system that is favorable for their long-term development (Vaeyens, Lenoir, Williams, \& Philippaerts, 2008). On the premise that performers with potential should be carefully nurtured - with sports looking to protect their investment - many TID programs continue to provide support that essentially smoothens or streamlines development (i.e., support that softens, removes or avoids challenges; e.g., New Zealand's Pathway to Podium program, 2013). However, recent work has argued that many of the problems faced by performers during and at the end of their time on talent pathways are symptomatic of such a trauma-free journey. In line with research on the non-linearity of talent development (e.g., Abbott, Button, Pepping, \& Collins, 2005) and work that has started to explore challenges in more detail (e.g., Howells \& Fletcher, 2015; Sarkar, Fletcher, \& Brown, 2015), the suggestion that "talent needs trauma" has therefore gained momentum (Collins \& MacNamara, 2012). However, as the foundation and implications of this proposal have only lately come under scrutiny - with some questionable suggestions being made on the causative role and benefits of non-sport and life trauma in the development of sporting talent (e.g., Howells \& Fletcher, 2015; Rees et al., 2016; Sarkar et al., 2015) - there is a need for work to deepen our understanding of what these traumas are, what they can do, and what they require of the performers who face them.

Previously, the development of talent was often viewed as a relatively linear process; in short, talented individuals were perceived to develop both steadily and smoothly (Tinning, Kirk, \& Evans, 1993). It is now widely agreed, however, that the development of talent is a non-linear process characterized by stages and trajectories that are handled in individual ways 
(Abbott et al., 2005; Vaeyens et al., 2008). More recently, work has identified that challenges during development - and, of course, how these are handled - play a key and positive role in successful progress (MacNamara, Button, \& Collins, 2010b). In contrast, or at least in addition to work that has focused on effective ways to smoothen the development process, it has thereby been argued that such support is built around the "rocky road to the top" (Collins \& MacNamara, 2012).

Akin to ideas on acquiring mental toughness and resilience (Bull, Shambrook, James, \& Brooks, 2005; Crust \& Clough, 2011; Sarkar \& Fletcher, 2014), Collins and MacNamara (2012) more specifically argued that talent needs trauma. To be clear, this work suggested that talented performers need some degree of challenge to facilitate the training, use, and refinement of fundamental psycho-behavioral skills and confidence to deploy them, thereby, facilitating optimal development. Indeed, posttraumatic growth theory suggests that cognitive and behavioral development can occur when an established set of schemas are challenged by relevant trauma that the individual then proactively deals with (Tedeschi \& Calhoun, 2004). Of course, it is clearly important to carefully define trauma in these instances. As highlighted by Collins, MacNamara and McCarthy (2016), an Oxford English Dictionary definition of trauma means "literally wound". While trauma may therefore relate to major damage, it can also relate to more minor harm or impairment; the latter of which would reflect the scale of trauma usually experienced (and preferred) in talent development contexts; although the emotional impact may be temporarily more severe. Such minor traumas could be events such as failing to meet performance expectations, de-selection, or a change in training group. To remain consistent with prior research (e.g., Collins \& MacNamara, 2012; Collins et al., 2016; Sarkar et al., 2015), a trauma is therefore defined in this paper as a memorable challenge that was perceived to disrupt a performer's development 
(please note that all references to trauma from this point should be read with this definition in $\operatorname{mind})$.

In line with the proposal that talent needs trauma (Collins \& MacNamara, 2012), Howells and Fletcher (2015) studied the autobiographies of Olympic swimming champions and reported on the apparently close correlation between life trauma and high sporting success. Similarly, Sarkar et al. (2015) reported that adversity-related experiences, including those of a sporting, personal, and political nature, were deemed significant for 10 Olympic champions' development. More specifically, this adversity was associated with greater effort, desire, focused reflection, and learning. On this basis, Sarkar et al. advised that performers should be given regular opportunities to handle appropriate and progressively demanding stressors, be encouraged to engage with these challenges, and use debriefs to aid reflection and learning. Overall, studies such as Howells and Fletcher and Sarkar et al. have therefore appeared to suggest that adversity-related experiences can be catalysts or stimuli for later success and can often be related to athletes' personal lives. Notably, these points are in contrast, or at least in addition, to the main messages in Collins and MacNamara (2012), who proposed that talent needs trauma rather than is caused by trauma. Furthermore, other, more recent studies contrasting high medium and low achievers have not demonstrated such a clear relationship between trauma and achievement. In short, the exact role and operation of trauma seems to be in need of clarification.

To be clear, these positions vary in the extent to which they consider that successful development is due to characteristics and skills that are present either before (i.e., talent needs trauma) or after (i.e., talent is caused by trauma) a traumatic experience. The former suggests that trauma enables an application for focused testing and refinement of psychobehavioral characteristics and skills; the latter suggests that the genesis of key psychobehavioral characteristics and skills is from the trauma itself. In this regard, it is notable that 
Sarkar et al. (2014) recognized the need for future work to consider the temporal course of growth; indeed, the largely causative slant in their study may have come from exploring isolated episodes of adversity.

Against this distinction, much previous research has emphasized the role of a range of psychological factors in helping performers to navigate their way through the ups and downs of development. Informed by prior work on the psychological characteristics and skills of successful senior athletes (e.g., goal setting, commitment, concentration; Gould, Dieffenbach, \& Moffett, 2002; Orlick \& Partington, 1998), a body of work has since explored factors that aid the development of such athletes. Within this, some have focused on specific attributes or skills, such as coping (Hanton, Neil, \& Mellalieu, 2008), while others have considered more broad sets, such as mental toughness, resilience, and the psychological characteristics of developing excellence (Bull et al., 2005; Fletcher \& Sarkar, 2012; MacNamara et al., 2010b). In sum, this work has found that those who get to the top and stay there have a range of characteristics and skills that help them to behave and perceive in continually functional ways. In terms of the causative slant of some trauma-based research to date (e.g., Howells \& Fletcher, 2015; Sarkar et al., 2015), it therefore seems that more research is needed to explore the extent to which key psychological characteristics and skills are generated or tested and developed by trauma. In short, what is the detailed timeline of growth around trauma?

Therefore, reflecting the points raised in our Introduction, the goal of this study was to further explore the suggestion that talent needs trauma; or, more specifically, memorable challenges that disrupt a performer's perceived development (Collins \& MacNamara, 2012). Against this main goal, we had three specific aims. These were to explore (a) the perceived number and impact of memorable challenges in performers who had made it to the top level of their sport, (b) the nature of these challenges, and (c) the mechanisms that helped in handling and recovering from challenges. As such, our aims were developed to generate 
results on the number and nature of perceived challenges (for comparison with prior research; e.g., Howells \& Fletcher, 2015; Sarkar et al., 2014) as well as how these challenges exerted their influence by considering what participants brought into them and what they left with (to extend beyond prior research; e.g., Howells \& Fletcher, 2015; Sarkar et al., 2014). To achieve this, we heeded Sarkar et al.'s (2014) recommendation that continued work on trauma should consider the temporal course of growth through multi-methods research.

\section{Methodology}

\section{Research Philosophy, Design, and Methods}

As scientist-practitioners aiming to generate practically-meaningful knowledge, this study was underpinned by a pragmatic research philosophy (Giacobbi, Poczwardowski, \& Hager, 2005). In contrast to the top-down organization of other paradigms - where matters of ontology and epistemology should dictate the research process - pragmatists are driven by practical questions and methods by which they can be aptly answered (Giacobbi et al., 2005). As such, pragmatism rejects the tenets of pure positivism (i.e., the existence of a single reality and universal truths that can be objectively measured) and pure constructivism (i.e., reality is constructed by individuals and groups with no research finding more "correct" than another) and is not committed to any specific ontological or epistemological view. Crucially, however, the philosophy still guides all parts of the research process. In terms of the present study, we selected a relevant applied issue for study, focused on the process of experiencing trauma, considered ourselves co-constructors of knowledge, and ultimately aimed to identify tangible applied artifacts rather than generalized truths or purely subjective constructions (Denzin \& Lincoln, 2008; Giacobbi et al., 2005). To this extent, the study was aided by our own experiences of leading, assisting, and performing in elite sport talent pathways.

Pragmatism also promotes communication across different paradigms so that the most useful knowledge is generated (cf. Giacobbi et al., 2005; Sparkes, 2015). Against this view - 
and following Sarkar et al.'s (2014) recommendation for continued research on trauma - we considered that the aims of our study would be best addressed by a multiple methods design. Specifically, as our questions related to the number, nature, and mechanisms of traumas in performers' development, both quantitative and qualitative methods were deemed suitable. To clarify, both quantitative and qualitative methods were linked to the same main purpose (i.e., to shed light on trauma during development) but complete in themselves (Morse, 2003); an approach that is distinct to mixed methods research, which requires quantitative and qualitative methods to be fully integrated throughout the methodology (Sparkes, 2015).

\section{Participants}

Twenty elite performers were purposively recruited from a UK High Performance Centre (HiPC) consisting of 11 female and 9 male athletes aged between 20 and 29 years old $(M=23.23 ; S D=2.64)$. Performers were considered elite as they were currently competing at senior international level and were on a funding program overseen by their relevant sport's national governing body. Participants were also recruited on the grounds that they had medalled at senior international level, had achieved this level in the last two years, and had been on a formal development pathway for at least six years (i.e., a pathway managed by their sport's national governing body and in which they had been actively competitive). Their recent arrival at senior international level was intended to support accurate recall and counter issues that might have arisen in retrospective interviews with older performers. The criterion that participants had been on a pathway for at least six years was to increase the chances that they had gone through various stages and phases of development. As trauma can benefit performers across sport in general (rather than in specific types of sport; Collins \& MacNamara, 2011; Collins et al., 2016; Sarkar et al., 2015), our sample was also taken from different domains (athletics $=10$; downhill mountain biking $=2$; archery $=1$; equestrian $=1$; hockey $=2$; judo $=1$; football $=1$; lacrosse $=1$ ). The weighting towards athletics 
reflected greater access to this sport; these athletes did, however, compete in a host of different events (long distance running; steeplechase; 1500m; 800m; 100m; high jump).

\section{Procedure}

Ethical approval was obtained from the authors' institutional ethics committee and informed consent gained from each participant prior to their interview. To aid consistency, a semi-structured guide with open-ended questions and relevant follow-up probes and prompts was developed. This guide was informed by relevant literature on talent development and conducted on the base of a retrospective tracking protocol that has been previously used to elicit specific details on personal experience (Cruickshank, Collins, \& Minten, 2013; Ollis, MacPherson \& Collins, 2006). More specifically, and in line with the guidance in Sarkar et al. (2015), it was decided that each interview would be usefully framed by asking participants to firstly plot their perceived performance potential (Y-axis), starting from first involvement on their sport's pathway all the way to the present day (X-axis). This approach has been previously shown to increase the accuracy and insights of retrospective recall (Drasch \& Mattes, 2013)

The timelines were all gridded, made to the same scale, and participants decided on their highest level of perceived performance potential on this scale; as such, the ceiling of perceived potential was relative to each participant. As well as their perceived performance potential, participants were also asked to mark important events on their plotted line as well as key phases and stages in their development. For example, participants marked phases and stages in relation to aspects such as a change in coach, joining a new training group or moving up a competitive level. As well as providing information on the number of perceived traumas faced, this approach also allowed for later measurement on the comparative impact of each trauma (see Data Analysis section). 
Once this procedure was completed, qualitative data were then collected through subsequent discussion of the participant's unique timeline. More specifically, to elicit detailed perceptions on the nature and impact of the marked experience, questions were used to explore each identified phase, stage, and the experience itself (e.g., what occurred here? What happened before the trauma?), and probes and prompts used to clarify and explore relevant points (e.g., How did this experience impact your development? How did this impact on your perceived performance potential? How soon after the trauma was your performance affected?). To clarify, therefore, the interview guide was constructed to work around each individual's timeline and experience. Indeed, as retrospective interviews can be limited by recall and hindsight biases, we acknowledged this interaction by asking participants to carefully think through specific, chronologically-ordered phases and events in their development rather than sourcing broad reflections on unstructured experiences. It should also be noted that retrospective perceptions are not necessarily less accurate than real-time perceptions. Exploring "lived" rather than "live" experience can have many advantages; such as eliciting perceptions which have been critically reflected on over time and given meaning against the individual's refined view of both themselves and their history.

Prior to interviewing the 20 main participants, this full procedure was reviewed by the research team and piloted with five participants who met the inclusion criteria applied to the main participants (hockey $=2$; badminton $=2$; lacrosse $=1$ ). The ages of participants in the pilot study ranged from 22 to 26 years old $(M=23.4 ; S D=1.67)$. Following the pilot work, the only change required was to the instructions for drawing perceived performance potential timelines. More specifically, it was clear that there was a need to reinforce that this timeline should depict perceived performance potential (i.e., the highest level of performance of which they thought themselves capable) rather than solely competitive results (i.e., the performance and outcomes that they actually delivered). Beyond this, all interviews were conducted as 
described in the preceding paragraph by the first author. These lasted between 40 and 60 minutes $(M=54.20)$ and were audio recorded for later transcription and analyses.

\section{Data Analyses}

Quantitative Analysis. Reflecting our multiple methods approach, data analyses were split into two parts. First, a quantitative analysis was undertaken to (a) calculate the number of memorable traumas reported by participants during their development, (b) calculate the frequency of different types of trauma, and (c) calculate the impact of these traumas on performance potential. To address the latter, each grid on the graph was taken as 1 unit. The impact of each trauma was then calculated by (a) taking the vertical distance between the point where the trauma occurred and where the following decrease or increase in potential reached its lowest or highest point, and (b) working out the percentage change in potential against the level at the time the trauma occurred. So if a trauma was followed by a drop of 1 unit from a perceived potential of 5 units then this had a magnitude of $20 \%$ (i.e., $1 / 5 \times 100=$ 20\%). An example of a perceived drop is shown on Figure 1.

If a trauma was followed by an immediate decrease in potential, we also calculated the "rebound" after the lowest point had been reached; or, more specifically, the percentage increase in potential from the lowest point after a trauma to the highest immediate point that followed. So if the lowest point reached after a trauma was at 8 units and the highest subsequent point in the rebound was 10 units then this was calculated as having a magnitude of $25 \%$. (i.e., $10 / 8 \times 100=125 \%$; thus a $25 \%$ increase on their prior potential). An example of a perceived rebound is shown in Figure 1. By calculating relative percentages, data were therefore relative to each participant and normalized to allow for comparison across participants. As we were not concerned with the time that it took participants to recover from traumas, no such calculations were made in this respect. To confirm, all of the final traumas recorded on each participant's timeline were perceived as "complete" (i.e., the full drop and 
rebound was perceived to have been experienced); therefore no athletes were in the midst of a trauma during their interview.

Qualitative Analysis. On completing the quantitative analysis, an entirely separate inductive content analysis was then conducted on the qualitative data to identify factors that were perceived to have helped the participants handle and recover from traumas. To be clear, these data consisted of quotes that related to each participant's experience of the reported traumas on their timeline. As such, any data on other aspects of development that were not related to trauma were not included in the analysis. Following the procedure in Côté, Salmela, Baria, and Russell (1993), the data were read and re-read several times, raw data units were transformed into thematic hierarchies by creating tags (e.g., "use of motivation to recover from first competition setback"; "management of social support after missed selection for World Championships"), grouping similar tags into sub-themes, and then organizing these sub-themes into a distinct framework of higher order themes.

\section{Trustworthiness}

As trust and rapport shape the process and outcomes of interviews (Sparkes \& Smith, 2009), these features were enhanced by the first author's (a) full time role in the center where the participants trained, performed, or were supported; (b) knowledge of each participant's career, and (c) awareness of the traumas of elite sport as an experienced practitioner. For the qualitative data analysis, transparency was aided by use of qualitative analysis software (QSR NVIVO 9). For example, conceptual memos were recorded to log the rationale behind the first author's interpretation and give a stimulus for discussion in the research team (Davis \& Meyer, 2009). A journal was also kept by the first author to reflect on the research process and how any biases were interacting with the evaluation and categorization of data (Patton, 2002). To support a recursive process, constant comparison was also employed to evaluate, evaluate, modify, and reinforce the developing findings (Corbin \& Strauss, 2008). The first 
author's interpretation was also challenged by presenting samples of meaning units and the themes to which they had been coded to the second and third authors (or critical friends; Faulkner \& Sparkes, 1999). Where alternative coding was suggested, discussion took place until agreement was reached. Finally, member checks were conducted over email and telephone so that participants could confirm the accuracy of their timeline and consider the accuracy, balance, fairness, and respectfulness of the quotes used in this paper (Sparkes \& Smith, 2009). No changes were made as a result of this process.

\section{Results}

The aims of this investigation were to explore (a) the perceived number and impact of memorable traumas faced by a sample of senior international athletes in their development, (b) the nature of these traumas, and (c) mechanisms that helped in handling and recovering from these traumas. Before considering our main results, it is notable that the progression graphs drawn by all participants were non-linear. Additionally, while the perceived stages of development were similar to stages outlined by Côté (1999), Figure 1 shows two examples of the unique nature of each journey. Further, all participants sampled a range of sports before investing in one and, on average, started to participate in their main sport at 9.6 years old. As such, no-one specialized early; although the sports that our sample participated in may have contributed to this finding. We now return to consider the results in relation our main aims.

\section{The Number and Perceived Impact of Memorable Traumas}

Table 1 details the distribution of memorable traumas experienced by participants, the average size of the perceived drop in potential immediately after each trauma, and the average magnitude of the consequent rebound. Notably, every participant reported that all memorable traumas were followed by an instant drop in perceived performance potential (i.e., nobody stated that a memorable trauma was followed by the immediate maintenance of, 
or a positive difference to their potential). Apart from one trauma for one participant, all also reported later rebounds in potential that exceeded the magnitude of each initial drop.

While the average magnitude of the drops in potential were relatively consistent over traumas 1 to 4, the fifth trauma had the largest negative impact and preceded a similar size of rebound. In short, the size of the rebound was similar to the size of the setback, therefore suggesting less growth from this trauma as compared to traumas 1 to 4 . In this way, the later traumas may have provided more of a test and confirmation of skills established as opposed to another situation to test then grow. Clearly, this suggestion must be treated cautiously given that it is based on two participants. Perhaps more robust, the average magnitude of each rebound increased over traumas 1 to 4; suggesting an improvement in trauma-relevant skills as well as learning effects. Finally, the average age at the time of the first memorable trauma was 16 years old, aligning with sport investment. The average age of the second trauma was 19.5 years old, but incidence ranged from 16 to 25 years old.

\section{The Nature of Memorable Traumas}

Table 2 illustrates the nature of the memorable traumas that were reported and their frequency across all participants. Almost all perceived traumas were sport-based with the rest attributed to illness (all illness-related traumas were reported as perceived trauma 1 or 2 by these participants). No personal life events were reported as traumas.

\section{Supporting Mechanisms}

When asked to reflect on factors that facilitated recovery from perceived traumas, all participants were able to identify a number of supporting mechanisms. These mechanisms were derived from the qualitative part of this study and are shown in Table 3. Specifically, these mechanisms were psychological characteristics, social support, and learning factors. We now describe each area and how they helped athletes to rebound from traumas. 
Psychological characteristics. All athletes highlighted motivation as a key factor for stimulating and driving recovery from trauma. Notably, motivation was mentioned by all participants when recovering from their first memorable trauma; as per the following participant who had experienced a sustained period of underperformance:

I stagnated in terms of my results at national level competitions and I did not manage anything internationally. So I guess I caught a bit of a reality check. I wanted to be an international athlete, I wanted to show that. (1500m runner)

Notably, this motivation was present before the trauma occurred with this event providing a significant "reality check" rather than any new skills. Similarly, self-belief was consistently identified as a factor in helping participants to handle memorable traumas:

I think just the fact that I hadn't been chosen [for the national squad] made me think I know that I'm better than that. I'm better than you think and know I can perform better. So it was a challenge. (Hockey player)

Once again, this event and the steps that followed were managed through the self-belief that the performer brought into this "proving experience". Participants also commonly referred to an increased focus on a specific goal post memorable trauma; thus taking a previous skill but emphasizing it in light of its' recognized importance: “After coming back from that injury I felt I switched on more. I knew I needed to make each training session and each rep count" (Track \& field athlete). As implied here, focus after a trauma often had general (i.e., make each session count) and specific (i.e., make each rep count) elements. Indeed, the ability to be clear and channel attention onto the most significant factors was referenced by many:

After that performance I knew I just had to focus on me and the line, not get absorbed into someone else's race as I have done before. Just be confident, focus on me and what I was about to do. Get out and get in a good position. (100m sprinter) 
As another key psychological characteristic, participants noted how self-awareness of their strengths and weaknesses helped them to handle and then recover from traumas:

There were girls I was better than who were beating me in cross country; for me it didn't matter. Cross-country wasn't my biggest strength and I knew when it came to track season I would be ahead .... That's where it mattered. (Long distance runner) Participants also reported a tendency for protective attributions. Indeed, by crediting success to internal, stable, and controllable factors and failure to external, transient, and uncontrollable factors, this helped to maintain self-esteem and motivation:

I tried to balance full-time studies with training very hard for the Commonwealths. I was run down, got very ill and kept trying to train through it, and I went to the commonwealth's completely unprepared .... I had taken on too much, so then when Olympic year came I took a sabbatical to focus on training. (Steeplechase runner) As a crucial qualification, this self-protective style of attribution was perceived as beneficial but at certain times and under certain conditions; a point which further stresses the merits of being able to select and deploy the best pre-existing skills for each trauma. Indeed, deeper and more frank appraisals were also indicated as important; something that was characteristic of the reflection and evaluation subtheme. One participant gave a particularly clear example of the value of accurate and measured introspection on "the why" of a trauma:

I had it in my head I wasn't as fit as the year before and wouldn't be able to run three races in three days. So I didn't really sprint for the line like I should have, I ended up getting dipped basically. It was well within my ability to make it, it was really just a confidence thing. I knew what I needed to do next time. (800m runner)

As described in this quote, the connection between inappropriate self-handicapping and a frustrating result was recalled as a key moment. Importantly, there also appeared to be a clear learning outcome from this episode in that the athlete reflected on why they failed to 
execute their race plan and then adjusted their approach so that this trauma would be less likely to re-occur, something that we pick up when discussing learning factors later.

Social support. As well as core psychological characteristics, participants also all described the value of identifying and using social support. Notably, nobody reported any particular parental pressure to partake or invest in their sport. In fact, parents were perceived to have played a key supportive role, as did particular coaches. For example, such support during early traumas was regularly mentioned; including parents sacrificing their time and driving the athlete to training or competition and coaches going above and beyond their role to support development. For example, one participant outlined the support they received in relation to the trauma of leaving school:

I felt pressure to get a job and pay my way. That's when I applied for a scholarship to go and ride in a team, which I got .... From then on I had trials and kept getting selected ... . My parents were supportive and seemed happy with my decisions. I think it was because I was doing something I really wanted to do. (Mountain biker) Coaches were also used to help participants' cope with trauma, often via their understanding the participant's needs and maintaining a sense of calm and confidence:

My coach would always seem calm, even when I messed up. He just knew to give me time to myself after selection and we'd talk about it the next day. He kept confident I could make it, we'd just figure out what I needed to do. (Football)

As suggested, this trauma was managed by the coach's mutual understanding of how best to support the participant. Indeed the value of coherence in participants' networks - and using this coherence in a proactive manner - was stressed in all interviews.

Finally, as well as identifying and using social support, it was also recognized that this support had to be managed. Indeed, represented by the theme management of social support, participants described the importance of knowing when to use social support; especially when 
their current schedule required sustained energy and focus (e.g., during a period of technical refinement). For example, one participant described adjusting their relationship with friends who were (and would continue to be) a major support in helping to switch off from sport:

After that [memorable trauma] I made the decision not to be going out partying with my friends. I wanted to concentrate on training and knew I couldn't do both. I made sure I still saw my friends but just in different circumstances. (1500m runner)

Once again, this supporting mechanism was present before the trauma was experienced but subsequently refined so that it could be used in a different and more conducive way.

Learning factors. Distinct from the aforementioned skills and attitudes, participants also noted the value of drawing on prior or vicarious experience to rebound from memorable traumas. Indeed, applying learning from personal experience was continually referred to from discussions of the second trauma onwards (as indicated by many preceding quotes). Specifically, effective rebounds were characterized by the ability to frame traumas against prior experiences, thus providing a "big picture" and re-igniting a desire for excellence:

So I guess [my previous] challenges have helped me mature in terms of helping me deal with challenges [that have followed later]. I put things into perspective and figured out exactly what I needed to do and be focusing on. (Distance runner) As suggested by this quote, being able to rationalize traumas with a broadened view helped participants to adapt and optimize the efficiency of their development. There additionally seemed to be a large element of resourcefulness when dealing with traumas, as particularly enabled through applying learning from peer experience:

When I was 17, I didn't perform well but there was one other archer on our squad who won individual gold in Cyprus on a junior European Cup. This made me realize well if he can do it why can't I? (Archer) 
In short, if one had not experienced a trauma, or a particular type of trauma, before then the meaning and lessons on how to respond effectively could often be taken from others. Once again, this mechanism was taken into - rather than caused by - the trauma faced.

\section{Discussion}

The purpose of this study was to deepen understanding on the role of trauma during the development of successful senior performers. We aimed to study perceptions of (a) the number and impact of perceived memorable traumas, (b) the nature of the traumas, and (c) mechanisms that helped with handling and recovery. By exploring the temporal course of growth using multi-methods (cf. Sarkar et al., 2015), this research has supported Collins and MacNamara's (2012) proposal that talent needs trauma and, perhaps more importantly, added depth to the description and explanation of how trauma might impact development.

First, it was notable that memorable traumas were not reported by participants until 7 years after starting their chosen sport, around 16 years old on average. Perhaps accounting for why traumas were not reported earlier, it is telling that the first perceived trauma was faced in the initial phases of investment. As investment usually requires higher levels of time and commitment (Cote, 1999), it may be that traumas at this point had a more significant impact than those faced before; especially as performers tend to expect to progress gradually and smoothly (cf. Henriksen \& Mortensen, 2014). In short, traumas at earlier ages may not have been perceived as memorable due to lower levels of personal investment and less worry (or awareness) over what this trauma may have meant for the present or future.

Regarding the impact of traumas, it was notable that perceived potential after these events was almost always greater than it was before. Positive rebounds also increased with each trauma except for those who reported five memorable events. Although a definitive lesson from this point is clearly not possible, this trend from trauma 1 to 4 suggests that the rebound mechanisms (i.e., psychological characteristics, social support, learning factors) may 
have been increasingly enhanced over each trauma. Accounting for the marginal last rebound for the two participants who reported a fifth trauma (illness and difficulty with a coach relationship), this might reflect the use of mechanisms that had already been added to, reinforced, or honed several times or a situation that offered little new learning. This last trauma may have thereby been more of a proving experience than chance to grow. In terms of the nature of the memorable traumas, almost all were of a sporting nature with a small number related to illness. Counter to previous work (Fletcher \& Sarkar, 2012; Howells \& Fletcher, 2015), there was a distinct lack of life or non-sport trauma reported; a finding more in line with the primarily sporting challenges reported in Sarkar et al. (2015) and by Collins, MacNamara and McCarthy (2016). While it is impossible and illogical to separate the "person" from the "performer," it is telling that the present study's use of primary data acquired for research purposes - as per Collins, MacNamara and McCarthy (2016) and Sarkar et al. (2015) - elicited notably different findings to research that has acquired secondary data from publicly consumed autobiographies (Howells \& Fletcher, 2015). Accordingly, life and non-sport trauma may clearly have an impact on the individual but the extent to which these are directly linked to development in sport and one's sporting identity may be questionable.

In terms of the mechanisms for handling and rebounding from traumas, our results support prior work on the role of psychological characteristics of developing excellence (e.g., MacNamara et al., 2010a). Indeed, numerous characteristics found in this study overlap with those reported in this area of research to date (e.g., motivation; self-belief; focus). In line with constructs that reflect a constellation of attributes (e.g., resilience; Sarkar \& Fletcher, 2014) our findings point to the significance of having a variety of skills and attitudes that are then combined and deployed at appropriate times; what might be thought of as the skills which underpin the attribute. Of specific note, motivation seemed to be particularly useful 
for early traumas; perhaps due to it being a strong driver for investing in a sport. Indeed, when performers start to devote more time and energy into their sport, it seems logical to suggest that they would be particularly motivated to overcome early traumas.

Regarding social support, this mechanism has been well-reported in prior work (e.g., Galli \& Vealey, 2008; Gould et al., 2002; Rees \& Hardy, 2000). While this study didn't intend to delve into all of the different types of social support used by performers, the results did suggest that this feature provided benefits when coping with and rebounding from a trauma. Indeed, Morgan and Giacobbi (2006) have already noted that athletes' use of social support and relationships can be valuable for dealing with challenges and adversity.

Pertinently, the findings in our study also highlighted the role of autonomy in managing social support. Autonomy and control have previously been linked to individuals' decisions to make relevant sacrifices leading to higher success rates (Fazey \& Fazey, 2001). As such, it is not just the availability and use of social support that seems to help negotiate traumas but also how it is proactively managed so that performers get what they want when, where, and how they want it.

As the final mechanism, further evidence has been found for the key role of learning factors in response to memorable traumas. Specifically, we found that participants did not only use psychological characteristics and others to get through traumas but also relied on basing their response on personal or others' experience. Closely integrated with reflection and evaluation (or the process by which accurate and meaningful lessons were formed), this finding suggests that, while learning can clearly be stimulated after a challenge (Sarkar et al., 2015), it is the learning that athletes bring into the challenge that also seems crucial. Indeed, principles of posttraumatic growth suggest that individuals need to manage any initial distress before constructive cognitive processes can occur (i.e., changes in thinking which lead to enhanced functioning; Calhoun, Tedeschi, \& Tedeschi, 1999). 
Beyond the core results, two other particularly significant and distinguishing findings must be mentioned. Firstly, participants did not report that they had to use or learn anything particularly new when coping with their memorable traumas (e.g., a new skill or source of support). Rather, their accounts suggest that they used and refined what they already had or did (e.g., increased their focus in each training session; managed existing social support). As such, while traumas were perceived to have caused drops in potential, they certainly did not appear to be the cause of the consequent rebound. As suggested throughout our Results and Discussion so far, it was the mechanisms that the participant brought to the traumas that seemed to be most important in how traumas were negotiated. Second, in no case was the successful negotiation of a trauma attributed solely to new information or support provided by other people. Indeed, solutions to drops in potential appeared to be chiefly self-driven.

Considering the applied implications of our findings, causative relationships were clearly not identified through the design employed. However, based on the descriptions provided by our participants and prior work (Collins \& MacNamara, 2012; Sarkar et al., 2015), it does seem realistic to suggest that talent does benefit from certain types of trauma during development. Our findings also suggest that such experiences are not the source of developing entirely new skills, attitudes, and learning but rather, more of a proving experience where already present (but not necessarily high-level) skills, attitudes, and learning are tested and refined. Thereby, trauma can offer a chance to add to, hone, or reinforce one's abilities and apply perspective to development. Building on prior advice (e.g., Collins \& MacNamara, 2012; Crust \& Clough, 2011; Sarkar et al., 2015), it therefore seems important that performers are encouraged to deal with traumas that they experience head on. The athlete's support network will of course be integral for this, especially for avoiding rapid resolution (when appropriate). Indeed, rapid resolution may prevent an athlete's assumptions being sufficiently tested, thereby limiting or nullifying any schematic 
change or later post traumatic growth that could contribute to long-term success (Tedeschi \& Calhoun, 2004). Certainly, self-regulated learners can acquire core skills to support current and future learning, such as self-monitoring, emotional management, investing in selfimprovement and seeking help from others (Petlichkoff, 2004). In contrast, individuals without these skills may ultimately take limited responsibility, typically relying on others and attributing failures to maladaptive reasons (MacNamara et al., 2010b).

Moreover, our results further support the assertion that athletes' should be challenged regularly to aid growth and avoid stagnation (Bull et al., 2005; Collins \& MacNamara, 2012; Crust \& Clough, 2011; Sarkar et al., 2015). To be clear, we do not suggest that memorable traumas are forced by program leaders; indeed, the memorability of a trauma is clearly a matter of personal interpretation. Rather, it seems reasonable to promote, in accordance with prior work (Collins \& MacNamara, 2012; Crust \& Clough, 2011; Galli \& Reel, 2012; Sarkar et al., 2015), the inclusion of appropriately structured and managed trauma (or challenge) in talent programs. Specifically, trauma that (a) elicits a challenge rather than a threat state (Kassam, Koslov, \& Mendes, 2009), (b) is given to athletes with sufficient skills, attitudes, and prior learning to take it on and benefit, (c) is delivered in a supportive environment, and (d) elicits outcomes that can all be framed with a developmental lens. Indeed, deliberate experience has already been identified as an effective way to aid the development of expertise (cf. Durand-Bush \& Salmela, 2001; Ollis et al., 2006). As an example of structured trauma, athletes may be intentionally promoted to a level or squad that will be difficult for them to handle on a technical and tactical level (i.e., being exposed on some level is almost guaranteed). Crucially, however, this challenge is provided to athletes who have proactively developed a base of psychological skills that will help them to cope with the challenge (e.g., focus; self-belief). Additionally, program leaders and staff will help these athletes to prepare for the challenge (e.g., developing performance goals and plans) and then focus on their 
learning around the performance-specific goals and plans in the review process. Indeed, the provision of appropriate support from program leaders and staff will be integral to maximizing growth from such structured trauma.

Further, our results stress the need to proactively and intentionally develop supporting mechanisms in advance of young athletes' inevitable challenges. This point extends Sarkar et al.'s (2015) advice on the need to provide more opportunities to take on, engage with, and debrief traumas. Indeed, as well as providing regular traumas and facilitating learning post hoc, our findings point to the importance of ensuring that athletes have the appropriate skills, attitudes, prior learning, and confidence $a$ priori. So, rather than placing performers into "sink or swim" situations (please note that we do not suggest that Sarkar et al. advocate this), our findings illustrate that floats and armbands also need to brought to the pool. Indeed, while research has found that many performers benefit from adversity, our results, anecdotal evidence, and common sense suggest that those who do not have sufficient "up-front skills" will be less likely to reach their potential and more likely to withdraw from sport. As such, talent appears to need trauma rather than be caused by it (cf. Howells \& Fletcher, 2015).

Of course, this study was not without limitations. For example, as data was collected retrospectively then there is a risk of interaction from hindsight and self-preservation biases, as well as issues with recall accuracy. Furthermore, our design also did not allow us to draw concrete conclusions on any causative relationship between the mechanisms reported by our participants and their ultimate development and success; neither did it allows us to disprove suggestions in other work that implies causative relationships between trauma and progress (e.g., Howells \& Fletcher, 2015). Notwithstanding this shortcoming, the evidence presented here does suggest that traumas act as proving experiences rather than the origins of specific characteristics or skills. In this regard, we also ask the reader to consider some characterizing traits that support this message (Sparkes \& Smith, 2009). As well as approaches to optimize 
trustworthiness (cf. Methodology section), methodological coherence was aided by framing our questions, selection of high caliber participants, methods, analyses and interpretation in a pragmatic research philosophy (Giacobbi et al., 2005). As pragmatic studies aim to develop useful ways of addressing applied challenges (Giacobbi et al., 2005), we also ask the reader to consider the contribution of our findings to practice-oriented theory and consultancy. To summarize, our findings suggest that practitioners should: avoid (or at least be highly skeptical of) making performance-based decisions (e.g., selection; provision of additional support) on the basis that an athlete has faced non-sport or life traumas; help performers to proactively develop psychological characteristics of developing excellence and social support that can be brought to traumatic experiences (MacNamara et al., 2010a, 2010b); use trauma as a "skill-proving" rather than "skill-causing" experience; be mindful that rapid resolution might lead to sub-optimal growth from trauma; support post-trauma learning; and, finally, proactively structure and manage appropriate trauma in TD programs. While some of these recommendations are consistent with other studies in this developing area, it should be noted that many are also in notable contrast to the suggested causative role and benefits of nonsport or life trauma (e.g., Howells \& Fletcher, 2015; Rees et al., 2016; Sarkar et al., 2015). In conclusion, this study has provided further evidence that traumas, or memorable challenges that disrupt a performer's development, play an important part in the development of talent. Specifically, our findings support the proposal that talent needs rather than is caused by trauma; with this trauma primarily being of a sporting nature and negotiated with a host of skills that are brought to the experience. Indeed, traumas seem to be more of a proving experience than a means to learn entirely new skills or approaches, or to simply be resilient. Finally, we hope that this study stimulates continued research on the processes and mechanisms that shape performers' interpretations of, and responses to traumas; including 
longitudinal and action-research based inquiry that tracks the ups and downs of development, how these can be prepared for, and how they are reacted to in real time. 


\section{References}

Abbott, A., Button, C., Pepping, G-J., \& Collins, D. (2005). Unnatural selection: Talent identification and development in sport. Nonlinear Dynamics, Psychology and Life Sciences, 9, 61-88.

Bull, S. J., Shambrook, C. J., James, W., \& Brooks, J. E. (2005). Towards an understanding of mental toughness in elite English cricketers. Journal of Applied Sport Psychology, 17, 209-227.

Calhoun, L. G., Tedeschi, R. G., \& Tedeschi, R. G. (1999). Facilitating posttraumatic growth: A clinician's guide. London: Routledge.

Collins, D., \& MacNamara, Á. (2011). Comments on 'Expert Performance in Sport and the Dynamics of Talent Development'. Sports Medicine, 41 (7). pp. 609-610

Collins, D., \& MacNamara, Á. (2012). The rocky road to the top: Why talent needs trauma. Sports Medicine, 42, 907-914.

Collins, D., MacNamara, Á., \& McCarthy, N. (2016). Super champions, champions, and almosts: Important differences and commonalities on the rocky road. Frontiers in Psychology, 6.

Côté, J. (1999). The influence of the family in the development of talent in sport. The Sport Psychologist, 13, 395-417.

Côté, J., Salmela, J. H., Baria, A., \& Russell, S. J. (1993). Organizing and interpreting unstructured qualitative data. The Sport Psychologist, 6, 55-64.

Corbin, J., \& Strauss, A. (2008). Basics of qualitative research: Techniques and procedures for developing ground theory (3rd ed.). London: Sage.

Cruickshank, A., Collins, D., \& Minten, S. (2013). Culture change in a professional sports team: Shaping environmental contexts and regulating power. International Journal of Sports Science and Coaching, 8, 271-290. 
Crust, L. \& Clough, P. J. (2011). Developing mental toughness: From research to practice. Journal of Sport Psychology in Action, 2, 21-32.

Davis, N. W., \& Meyer, B. B. (2009). Qualitative data analysis: A procedural comparison. Journal of Applied Sport Psychology, 21, 116-124.

Denzin, N. K., \& Lincoln, Y. S. (2008). Strategies of qualitative inquiry (3rd ed.). Los Angeles: Sage.

Drasch, K., \& Matthes, B. (2013). Improving retrospective life course data by combining modularized self-reports and event history calendars: experiences from a large scale survey. Quality \& Quantity, 47(2), 817-838.Durand-Bush, N., \& Salmela, J. H. (2001). The development of talent in sport. In R. N. Singer, H. A. Hausenblas \& C. M. Janelle (Eds.), Handbook of sport psychology (2nd ed., pp. 269-289) New York: Wiley.

Faulkner, G., \& Sparkes, A. (1999). Exercise as therapy for schizophrenia: An ethnographic study. Journal of Sport \& Exercise Psychology, 21, 52-69.

Fazey, D. M., \& Fazey, J. A. (2001). The potential for autonomy in learning: perceptions of competence, motivation and locus of control in first-year undergraduate students. Studies in Higher Education, 26, 345-361.

Fletcher, D., \& Sarkar, M. (2012). A grounded theory of psychological resilience in Olympic champions. Psychology of Sport and Exercise, 13, 669-678.

Galli, N., \& Reel, J. J. (2012). 'It was hard, but it was good': A qualitative exploration of stress-related growth in Division I intercollegiate athletes. Qualitative Research in Sport, Exercise and Health, 4, 297-319.

Galli, N., \& Vealey, R. S. (2008). Bouncing back" from adversity: Athletes' experiences of resilience. The Sport Psychologist, 22, 316-335.

Giacobbi Jr, P. R., Poczwardowski, A., \& Hager, P. F. (2005). A pragmatic research philosophy for applied sport psychology. The Sport Psychologist, 19, 18-31. 
Gould, D., Dieffenbach, K., \& Moffett, A. (2002). Psychological characteristics and their development in Olympic champions. Journal of Applied Sport Psychology, 14, 172204.

Hanton, S., Neil, R., \& Mellalieu, S. D. (2008). Recent developments in competitive anxiety direction and competition stress research. International Review of Sport \& Exercise Psychology, 1, 45-57.

Henriksen, K., \& Mortensen, J. (2014). Reality and dreams: A comparison of elite athletes' experienced career paths with young talented athletes' imagined career paths. Scandinavian Sport Studies Forum, 5, 69-91.

Howells, K., \& Fletcher, D. (2015). Sink or swim: Adversity- and growth-related experiences in Olympic swimming champions. Psychology of Sport and Exercise, 16, 37-48.

Kassam, K. S., Koslov, K., \& Mendes, W. B. (2009). Decisions under distress stress profiles influence anchoring and adjustment. Psychological Science, 20, 1394-1399.

MacNamara, Á., Button, A., \& Collins, D. (2010a). The role of psychological characteristics in facilitating the pathway to elite performance Part 1: Identifying mental skills and behaviors. The Sport Psychologist, 24, 52-73.

MacNamara, Á., Button, A., \& Collins, D. (2010b). The role of psychological characteristics in facilitating the pathway to elite performance Part 2: Examining environmental and stage-related differences in skills and behaviors. The Sport Psychologist, 24, 74-96.

Morgan, T. K., \& Giacobbi, P. R. (2006). Toward two grounded theories of the talent development and social support process of highly successful collegiate athletes. The Sport Psychologist, 20, 295-313.

Morse, J. M. (2003). Principles of mixed method and multi-method research design. In C. Teddlie \& A. Tashakkori (Eds.), Handbook of mixed methods in social and behavioral research, 189-208. London: Sage. 
New Zealand Sport (2013, May 5th). Pathway to Podium programme. Retrieved from http://www.sportnz.org.nz/news-and-events/media-releases-and-updates/articles/sportstalent-development-programme-announced

Ollis, S., MacPherson A., \& Collins D. (2006). Expertise and talent development in rugby referees: An ethnographic enquiry. Journal Sports Sciences, 24: 309-322.

Orlick, T., \& Partington, J. (1998). Mental links to excellence. The Sport Psychologist, 2, $105-130$.

Patton, M. Q. (2002). Qualitative research and evaluation methods (3rd ed.). Thousand Oakes, CA: Sage.

Petlichkoff, L. M. (2004). Self-regulation skills for children and adolescents. In M. R. Weiss (Ed.), Developmental sport and exercise psychology: A lifespan perspective (pp. 269288). Morgantown, WV: Fitness Information Technology.

Rees, T., \& Hardy, L. (2000). An investigation of the social support experiences of high-level sports performers. The Sport Psychologist, 14, 327-347.

Rees, T., Hardy, L., Güllich, A., Abernathy, B., Côté, J., Woodman, T., . . Warr, C. (2016). The Great British Medalists Project: A review of current knowledge on the development of the World's best sporting talent. Sports Medicine, 1-18.

Sarkar, M., \& Fletcher, D. (2014). Ordinary magic, extraordinary performance: Psychological resilience and thriving in high achievers. Sport, Exercise, and Performance Psychology, 3, 46-60.

Sarkar, M., Fletcher, D., \& Brown, D. J. (2015). What doesn't kill me...: Adversity-related experiences are vital in the development of superior Olympic performance. Journal of Science and Medicine in Sport, 18, 475-479. 
Sparkes, A. C. (2015). Developing mixed methods research in sport and exercise psychology: Critical reflections on five points of controversy. Psychology of Sport and Exercise, 16, 49-59.

Sparkes, A., \& Smith, B. (2009). Judging the quality of qualitative inquiry: Criteriology and relativism in action. Psychology of Sport and Exercise, 10, 491-497.

Tedeschi, R. G., \& Calhoun, L. G. (2004). Posttraumatic growth: Conceptual foundations and empirical evidence. Psychological Inquiry, 15, 1-18.

Tinning, R., Kirk, D., \& Evans, J. (1993). Learning to teach physical education. Sydney: Prentice Hall.

Vaeyens, R., Lenoir, M., Williams, A. M., \& Philippaerts, R. M. (2008). Talent identification and development programmes in sport: Current models and future directions. Sports Medicine, 38, 703-714. 